Article

\title{
Lactobacillus iners Cell-Free Supernatant Enhances Biofilm Formation and Hyphal/Pseudohyphal Growth by Candida albicans Vaginal Isolates
}

\author{
Samuele Sabbatini ${ }^{1}{ }^{(D}$, Sofia Visconti ${ }^{1}$, Marco Gentili ${ }^{2}\left(D\right.$, , Eleonora Lusenti ${ }^{2}$, Emilia Nunzi ${ }^{3}$, \\ Simona Ronchetti ${ }^{2}$ (D), Stefano Perito ${ }^{1}$, Roberta Gaziano ${ }^{4}$ (D) and Claudia Monari $^{1, *(D)}$ \\ 1 Department of Medicine and Surgery, Medical Microbiology Section, University of Perugia, \\ 06129 Perugia, Italy; samuele.sabbatini@gmail.com (S.S.); spallyvisco@gmail.com (S.V.); \\ stefano.perito@unipg.it (S.P.) \\ 2 Department of Medicine and Surgery, Pharmacology Section, University of Perugia, 06129 Perugia, Italy; \\ marcogentili1988@hotmail.it (M.G.); eleo95@gmail.com (E.L.); simona.ronchetti@unipg.it (S.R.) \\ 3 Department of Medicine and Surgery, University of Perugia, 06129 Perugia, Italy; emilia.nunzi@unipg.it \\ 4 Department of Experimental Medicine, University of Rome Tor Vergata, 00133 Rome, Italy; \\ roberta.gaziano@uniroma2.it \\ * Correspondence: claudia.monari@unipg.it
}

\section{check for}

updates

Citation: Sabbatini, S.; Visconti, S.; Gentili, M.; Lusenti, E.; Nunzi, E.;

Ronchetti, S.; Perito, S.; Gaziano, R.;

Monari, C. Lactobacillus iners Cell-Free

Supernatant Enhances Biofilm

Formation and Hyphal/Pseudohyphal Growth by Candida albicans Vaginal

Isolates. Microorganisms 2021, 9, 2577.

https://doi.org/10.3390/

microorganisms 9122577

Academic Editor: Clarissa J. Nobile

Received: 15 November 2021

Accepted: 10 December 2021

Published: 13 December 2021

Publisher's Note: MDPI stays neutral with regard to jurisdictional claims in published maps and institutional affiliations.

Copyright: (c) 2021 by the authors. Licensee MDPI, Basel, Switzerland. This article is an open access article distributed under the terms and conditions of the Creative Commons Attribution (CC BY) license (https:/ / creativecommons.org/licenses/by/ $4.0 /$ )

\begin{abstract}
Candida albicans is a commensal fungus of the vaginal mucosa and the principal etiological agent of vaginal candidiasis. Vaginal dysbiosis has been reported during vulvovaginal candidiasis (VVC), with a progressive decrease in Lactobacillus crispatus population and an increase in L. iners population. To date, the role of L. iners in VVC pathogenesis remains scarcely explored. Herein we investigated the in vitro effect of $L$. iners cell-free supernatant (CFS) on the ability of $C$. albicans to form biofilms. Biomass and metabolic activity were measured by crystal violet and XTT assays. Further, light microscopy was performed to determine the effect of L. iners CFS on biofilm cellular morphology. We found that $L$. iners CFS induced a significant increase in biofilm formation by C. albicans clinical isolates which were categorized as moderate or weak biofilm producers. This effect was associated with an enhancement of hyphal/pseudohyphal growth, and the expression levels of HWP1 and $E C E 1$, which are typical hyphae-associated genes, were upregulated. Overall, these results suggest that L. iners contributes to the pathogenesis of VVC and highlight the complexity of the interaction between $C$. albicans and vaginal lactobacilli. Understanding these interactions could prove essential for the development of new strategies for treating VVC.
\end{abstract}

Keywords: C. albicans; biofilm; L. iners; VVC; microbiota

\section{Introduction}

Vulvovaginal candidiasis (VVC) is the second most common cause of lower reproductive tract infections in women of childbearing age. It is estimated that $75 \%$ of all women will suffer from VVC at least once in their lifetime [1], and nearly $10 \%$ of them are bound to experience recurrence. Recurrent VVC (RVVC), defined as four or more episodes of infection every year, markedly affects the quality of life, considering the severity of symptoms and the resulting psychological stress [2,3]. C. albicans is the etiological agent of almost all cases of VVC [1,4]. C. albicans is a commensal fungus of the vaginal mucosa; several host-related features and behavioral risk factors can affect the onset of VVC, including pregnancy, hyperglycemia, immunosuppression, antibiotic or glucocorticoid therapies, genetic predisposition, as well as vaginal microbiota composition. Oral contraceptive use, intrauterine devices, some hygiene habits, clothing, and sexual practices are all considered to be major behavioral risk factors associated with VVC [5].

C. albicans pathogenicity is supported by a plethora of virulence factors, including its ability to form biofilms, morphological transition between yeast and hyphal forms, 
expression of adhesins and invasins on its cell surface, secretion of enzymes such as secreted aspartyl proteases and phospholipases, and production of candidalysin, a cytolytic peptide toxin $[6,7]$.

The ability of C. albicans to develop a complex biofilm on abiotic and biotic surfaces plays a key role in its pathogenicity [8]. Contrary to biofilms of other Candida spp., those formed by $C$. albicans display a more heterogeneous organization, formed by budding yeasts, a multilayer structure, and filamentous cells such as true hyphae and pseudohyphae, surrounded by extracellular matrix. The ability to form hyphae is critical for the development and maintenance of C. albicans biofilms. Indeed, hyphae are essential to supporting the structural integrity of biofilms and to provide a scaffold for the attachment of other yeast cells, pseudohyphae, as well as bacteria in polymicrobial biofilms [8-10].

Several studies have proposed that biofilm formation by C. albicans plays a crucial role in the development of vaginal candidiasis [11-15]. Wu et al. [16] supported the essential role of biofilm formation in the pathogenesis of vaginal candidiasis, demonstrating that histological damages of mucosal epithelial cells and local inflammation are associated with biofilm growth on the vaginal epithelium. In addition, it has been reported that C. albicans biofilm promotes the formation of persister cells, which are mainly responsible for the recalcitrance of vaginal candidiasis to antifungal drugs [14,17].

Lactobacillus spp. play a key role in maintaining vaginal health [18] and a decrease in their population, in particular of L. crispatus, is an important risk factor for the onset of vaginal infections $[19,20]$. However, recent studies have reported that not all Lactobacillus spp. are beneficial and protective in nature [21]. Tortelli et al. [22] showed that L. iners dominant communities were more permissive to vaginal colonization with potential pathogens such as C. albicans. Furthermore, Ceccarani et al. [20] demonstrated that VVC-positive women exhibited an increase in the relative abundance of L. iners, along with a decrease in that of L. crispatus.

L. iners is an unusual Lactobacillus species [23] with unique features. It shows a Gram-variable morphology, more complex nutritional requirements, produces few or no important protective factors, such as D-lactic acid and hydrogen peroxide; moreover, it is notable that it releases a cytolytic toxin [24]. L. iners dominance has been associated with adverse pregnancy outcomes [25,26] and infertility [27]. These characteristics have led to the hypothesis that $L$. iners can cause vaginal infections, including vaginal candidiasis $[21,22,28]$. Based on these assumptions, herein our main aim was to investigate the in vitro effect of L. iners cell-free supernatant (CFS) on the ability of C. albicans vaginal isolates to form biofilms. Further, we investigated the effects of L. iners CFS on biofilm cellular morphology, as well as on the expression of hyphae-associated genes.

\section{Materials and Methods}

\subsection{Subjects}

Fourteen nonpregnant, nondiabetic women aged between 18 and 48 years were enrolled at the Laboratory of Microbiology of the University Hospital "Santa Maria della Misericordia" (Perugia, Italy). Prior to enrollment, each of them completed a questionnaire indicating their health status and current symptoms of vaginal disease. All women signed an informed consent in accordance with the Declaration of Helsinki. This study was approved by the local ethical committee (Comitato Etico delle Aziende Sanitarie, Umbria, Italy) (CA 2020, 3802/19). All methods were performed in accordance with relevant guidelines and regulations. Each woman presented at least two of the following acute VVC signs and symptoms: vaginal discharge, itching, burning, and dyspareunia. Vaginal wet mount preparations were used to determine the number of polymorphonuclear cells per microscopic field, presence or absence of lactobacilli, and presence or absence of yeast and pseudohyphae/hyphae. The absence of other possible etiological agents responsible for vaginal infections was assessed by microbiological analysis. 


\subsection{Collection of $C$. albicans Isolates}

All details pertaining to sample collection methods have been previously described $[29,30]$. Briefly, vaginal swabs from each patient were plated on CHROMagar Candida (VWR International P.B.I, Milan, Italy) and incubated at $37^{\circ} \mathrm{C}$ for $48 \mathrm{~h}$ under aerobic conditions. Routine methods were used to identify yeast colonies, followed by confirmation with matrix-assisted laser/desorption ionization time-of-flight mass spectrometry (MALDI-TOF, bioMèrieux, Marcy-l'Étoile, France). All C. albicans strains were stored at $-80{ }^{\circ} \mathrm{C}$.

\subsection{Microorganisms, Growth Media, and Growth Conditions}

C. albicans ATCC 10231 and L. iners ATCC 55195 were purchased from the American Type Culture Collection (ATCC). C. albicans clinical isolates and reference strain were cultured on yeast extract peptone dextrose (YEPD) agar plates at $30{ }^{\circ} \mathrm{C}$ under aerobic conditions. L. iners ATCC 55195 was routinely grown in New York City (NYC) III broth at $37^{\circ} \mathrm{C}$ for $24 \mathrm{~h}$ under anaerobic conditions. All microbial strains were freshly grown from frozen glycerol stocks (kept at $-80^{\circ} \mathrm{C}$ ) before each experiment.

\subsection{Growth Curve and L. iners CFS Preparation}

An overnight NYC III broth culture of L. iners ATCC 55195 was 1:100 diluted in brain heart infusion (BHI) broth and incubated at $37^{\circ} \mathrm{C}$ for $48 \mathrm{~h}$ under anaerobic conditions. At different timepoints $(0,2,4,6,24,28,32,48$, and $52 \mathrm{~h}), 100 \mu \mathrm{L}$ aliquots were withdrawn and diluted for CFU determination on NYC III agar plates, as previously described [31].

L. iners CFS was obtained at the end of exponential and decline growth phases. Briefly, after $24 \mathrm{~h}$ or $48 \mathrm{~h}$ of incubation, bacterial suspensions were centrifuged at $4000 \times g$ for $10 \mathrm{~min}$, and the supernatant was aseptically decanted and sterilized using a syringe filter with a pore size of $0.45 \mu \mathrm{m}$. The $\mathrm{pH}$ of the supernatant was measured before storing it at $-20^{\circ} \mathrm{C}$. Aliquots of L. iners CFS were immediately thawed before each experiment.

\subsection{Biofilm Formation and Biomass Quantification}

Biofilm formation was investigated as previously described by Gulati et al. [32]. Single colonies of $C$. albicans strains cultured on YEPD plates were inoculated into $5 \mathrm{~mL}$ of YEPD broth, followed by incubation at $30^{\circ} \mathrm{C}$ for overnight, and cell densities were then assessed by measuring absorbance at $\mathrm{OD}_{600}$. The correlation between $\mathrm{OD}_{600}$ and $\mathrm{CFU} / \mathrm{mL}$ was obtained by constructing a standard curve. Yeast cultures were then diluted with RPMI 1640 (with L-glutamine and $34.5 \mathrm{~g} / \mathrm{L}$ MOPS, w/o sodium bicarbonate; $\mathrm{pH}$ 7) at $1 \times 10^{7}$ cells $/ \mathrm{mL}$, and $200 \mu \mathrm{L}$ was transferred to each well of a 96-well microtiter plate (Corning Inc., New York, NY, USA). The plates were then incubated at $37^{\circ} \mathrm{C}$ for $1.5 \mathrm{~h}$ under aerobic conditions. Subsequently, the medium was discarded, and the wells were washed twice with $200 \mu \mathrm{L}$ PBS to remove nonadherent cells. The culture medium was replaced with $200 \mu \mathrm{L}$ of fresh medium, and the plates were incubated again for 24,48 , and $72 \mathrm{~h}$ under the same conditions.

Biofilm biomass was quantified using the crystal violet (CV) staining method, as previously described [31,32]. After incubation, the broth was discarded, and the wells were air dried for $45 \mathrm{~min}$. After washing twice with $200 \mu \mathrm{L}$ PBS, biofilms were stained with $110 \mu \mathrm{L}$ of $0.4 \% \mathrm{CV}$ for $45 \mathrm{~min}$, and then washed four times with $200 \mu \mathrm{L}$ distilled water. The CV bound to the biofilm was solubilized by adding $200 \mu \mathrm{L}$ of $95 \%$ ethanol, followed by incubation for $45 \mathrm{~min}$. Absorbance was measured at $\mathrm{OD}_{590}$ using a 96-well microplate reader (Tecan, Männedorf, Switzerland). Biofilm formation capability was determined as reported by Stepanovic et al. [30]. Clinical isolates were categorized into weak, moderate, or strong biofilm producers based on the calculated OD values for each strain and negative controls.

\subsection{Biofilm Metabolic Activity Assessment}

Biofilm metabolic activity was assessed by performing the 2,3-bis-(2-methoxy-4-nitro5-sulfophenyl)-2H-tetrazolium-5-carboxanilide (XTT) reduction assay, as previously de- 
scribed [32]. Fresh XTT (Invitrogen, Waltham, MA, USA) was prepared in PBS at a final concentration of $0.5 \mathrm{mg} / \mathrm{mL}$ and stored at $-80^{\circ} \mathrm{C}$. A phenazine methosulphate (PMS) solution was prepared at $0.32 \mathrm{mg} / \mathrm{mL}$ in sterile water. After biofilm incubation and cleaning, $200 \mu \mathrm{L}$ of XTT-PMS solution (9:1 ratio of XTT and PMS) was added to each well, followed by incubation in the dark for $2 \mathrm{~h}$ at $37^{\circ} \mathrm{C}$ under aerobic conditions. Absorbance was then measured at $492 \mathrm{~nm}$ using a 96-well microplate reader (Tecan, Männedorf, Switzerland).

\subsection{Effect of L. iners CFS on C. albicans Biofilm Formation}

The effect of L. iners CFS on C. albicans biofilm development was assessed according to the protocol described above. RPMI 1640 was mixed with L. iners CFS in a 1:1 ratio and added to Candida cultures both during the early adhesion and late maturation stages of biofilm development. In case of the control groups, biofilms were grown in RPMI 1640 mixed with fresh BHI broth. After $24 \mathrm{~h}$ of incubation, biofilm biomass and metabolic activity were determined, as previously described, and aliquots of CFS were used for pH determination.

\subsection{Effect of L. iners CFS on C. albicans Biofilm Morphology}

C. albicans clinical isolates and reference strain were incubated with $L$. iners CFS for $24 \mathrm{~h}$, and after CV staining, they were microscopically analyzed with an inverted light microscope (Eurotek by Orma, Milan, Italy). Images were captured using a digital camera $(200 \times$ and $400 \times$ magnifications).

\subsection{Quantitative Analysis of Genes Associated with C. albicans Hyphal Formation}

Total RNA was extracted from C. albicans ATCC 10231 and four clinical isolates, and the expression of hyphal-specific genes was determined. Briefly, total RNA was extracted from C. albicans biofilm cultures using TRIzol (Invitrogen, Waltham, MA, USA) and retrotranscribed into cDNA using the PrimeScript ${ }^{\mathrm{TM}}$ RT Reagent Kit with gDNA Eraser (Perfect Real Time) (Takara Bio Inc., Kusatsu, Japan). Quantitative real-time PCR (qRT-PCR) was performed using the QuantStudio 1 Real-Time PCR System (Applied Biosystems, Waltham, MA, USA). The analysis of ACT1, ECE1 (extent of cell elongation 1), and HWP1 (hyphal wall protein 1) expression levels was performed using SYBR Green Master Mix (Thermo Fisher Scientific, Waltham, MA, USA). Primer sequences were the same as those previously reported [29]. Real-time PCR was performed using the following cycling conditions: $3 \mathrm{~min}$ at $95^{\circ} \mathrm{C}$ and 40 cycles of $10 \mathrm{~s}$ at $95^{\circ} \mathrm{C}, 30 \mathrm{~s}$ of annealing at specific primer temperatures, and $45 \mathrm{~s}$ at $72{ }^{\circ} \mathrm{C}$. Ct values of target genes were normalized on the ACT1 housekeeping gene to obtain $\Delta \mathrm{Ct}$, while $\Delta \Delta \mathrm{Ct}$ was obtained as the difference between the average $\Delta \mathrm{CT}$ of the treated sample and the untreated sample. Relative changes in gene expression from qRT-PCR experiments were analyzed using the $2^{-\Delta \Delta \mathrm{Ct}}$ method.

\subsection{Statistical Analysis}

All analyses were performed with Prism GraphPad 7. Values represent mean \pm SEM of at least three independent experiments performed in triplicate. Data with normal distribution were analyzed using paired Student's $t$-test or one-way analysis of variance and Dunnett's multiple comparison test. For nonparametric variables, Wilcoxon matchedpairs signed-rank test or Kruskal-Wallis test and Dunn's multiple comparison test were performed. $p<0.05$ indicated statistical significance.

\section{Results}

\subsection{Growth Curve of L. iners}

L. iners is an unusual member of the human vaginal microbiota and does not show growth on de Man-Rogosa-Sharpe medium, which is normally used to isolate vaginal lactobacilli. To obtain CFS, L. iners was grown in BHI broth. As evident from Figure 1A, L. iners showed the ability to adapt and grow in BHI media after approximately $3 \mathrm{~h}$ of incubation. 
A

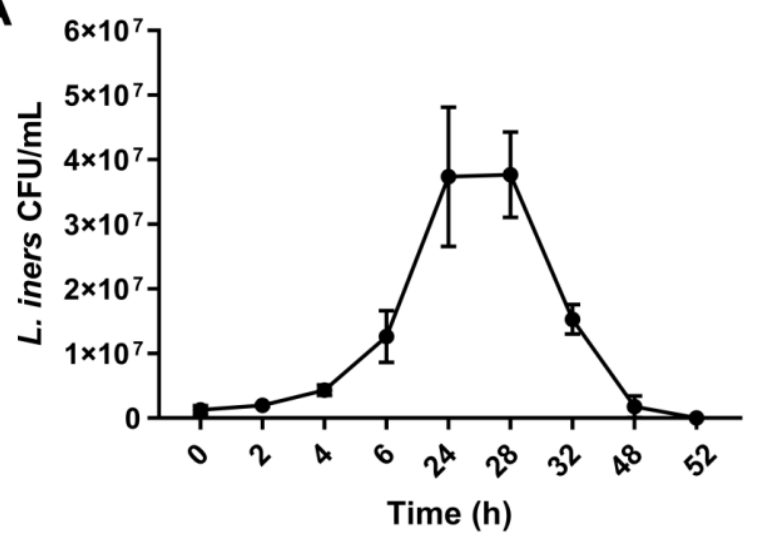

B

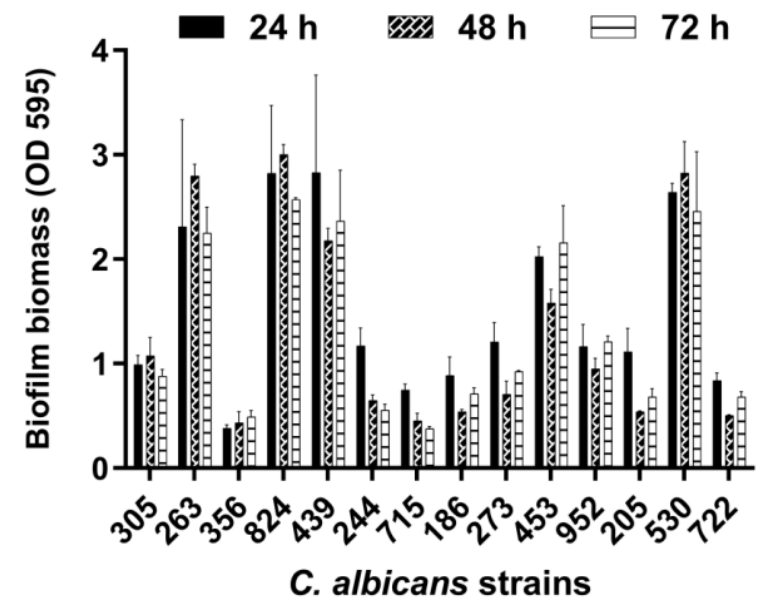

C

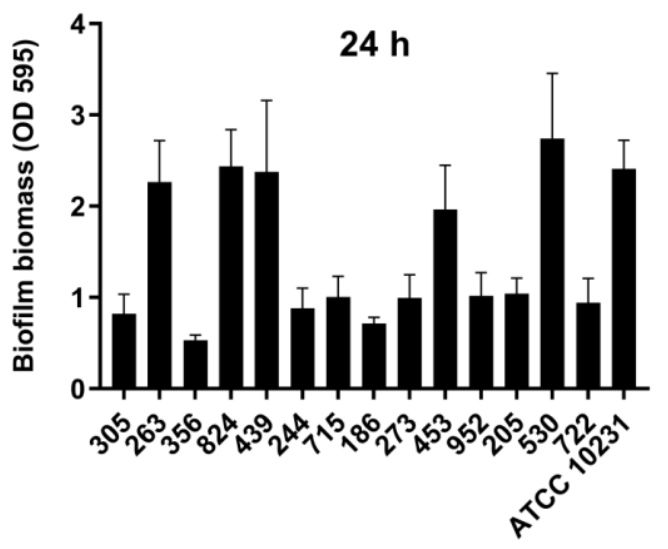

\section{C. albicans strains}

Figure 1. (A) Growth curve of Lactobacillus iners. L. iners ATCC 55195 was incubated for $52 \mathrm{~h}$ in brain heart infusion (BHI) broth, and bacterial growth was determined at selected time points. Values represent mean \pm SEM of colony-forming units (CFU)/mL from three independent experiments performed in duplicate. (B) Biofilm formation by Candida albicans clinical isolates in vitro. The isolates were grown for 24,48 , and $72 \mathrm{~h}$. Biofilm biomass was evaluated using the crystal violet staining method, and values represent mean \pm SEM of absorbance at $\mathrm{OD}_{595}$. Data are from at least three independent experiments with $n=6$. (C) Biofilm formation by C. albicans clinical isolates in vitro in RPMI 1640 + BHI broth. Biofilms were grown for $24 \mathrm{~h}$ using 1:1 RPMI 1640 and BHI broth. Values represent mean \pm SEM of absorbance at $\mathrm{OD}_{595}$ from at least three independent experiments with $n=6$. 
The growth curve exhibits the exponential growth phase from $6 \mathrm{~h}$ to $24 \mathrm{~h}$ of incubation, followed by the stationary growth phase, lasting for $4 \mathrm{~h}$, and ultimately the decline growth phase, beginning $28 \mathrm{~h}$ after incubation. CFS was recovered at the end of both the exponential (24 h CFS) and decline (48 h CFS) phases of growth. The average $\mathrm{pH}$ value was 6.0 (5.5-6.4) for both 24 and $48 \mathrm{~h}$ CFS.

\subsection{Biofilm Formation by Vaginal Isolates of C. albicans}

Fourteen clinical isolates of C. albicans obtained from women with VVC were analyzed for their ability to form biofilms under our experimental conditions. These isolates $\left(1 \times 10^{7} \mathrm{CFU} / \mathrm{mL}\right)$ were incubated in flat-bottomed 96-well microtiter plates in RPMI 1640 at $37^{\circ} \mathrm{C}$ for 24,48 , and $72 \mathrm{~h}$, followed by biofilm biomass quantification. We found that all strains formed a mature biofilm within $24 \mathrm{~h}$ of incubation, with a clear heterogeneity between them (Figure 1B). Based on biofilm biomass quantification, the isolates were categorized into strong, moderate, or weak biofilm producers [33]. Eight isolates (305, 244, 715, $186,273,952,205,722)$ were moderate biofilm producers $(0.60<\mathrm{OD} \leq 1.21)$, five isolates $(263,824,439,453,530)$ were strong biofilm producers (OD > 1.21), and one isolate (356) was a weak biofilm producer $(\mathrm{OD} \leq 0.60)$. Biofilm formation was also determined in $50 \%$ RPMI $1640-50 \%$ BHI media after $24 \mathrm{~h}$ of incubation at $37^{\circ} \mathrm{C}$ (Figure $1 \mathrm{C}$ ). We observed that the presence of $\mathrm{BHI}$ did not influence the ability of $\mathrm{C}$. albicans to form biofilms. Furthermore, in these experimental conditions, C. albicans ATCC 10231 showed the ability to produce a strong biofilm.

\subsection{Effects of L. iners CFS on C. albicans Biofilm Formation}

To evaluate the effects of L. iners CFS on C. albicans biofilm formation, $100 \mu \mathrm{L}$ of 24 or $48 \mathrm{~h}$ CFS in BHI was mixed with $100 \mu \mathrm{L}$ of each C. albicans isolate and C. albicans ATCC 10231 reference strain $\left(1 \times 10^{7} \mathrm{CFU} / \mathrm{mL}\right)$ in RPMI 1640, followed by incubation for $24 \mathrm{~h}$, as described earlier. Biofilm quantification was performed by biofilm biomass and metabolic activity determination. As is evident from Figure 2, seven of the nine moderate or weak biofilm producers displayed a significant increase in biofilm biomass and metabolic activity in the presence of L. iners 24 h CFS, whereas only two isolates ( 244 and 715 ) showed an increase in these parameters in the presence of L. iners $48 \mathrm{~h}$ CFS. 
305

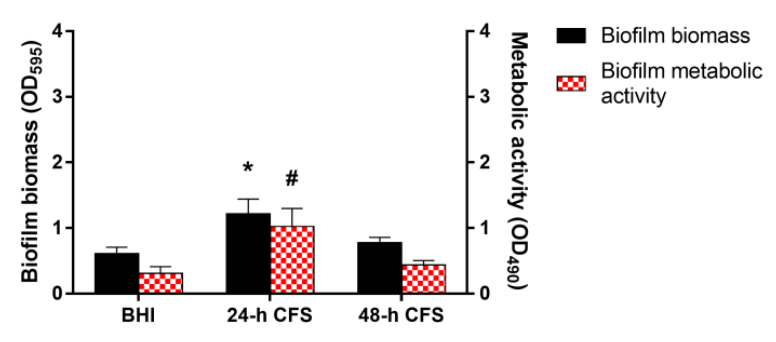

244

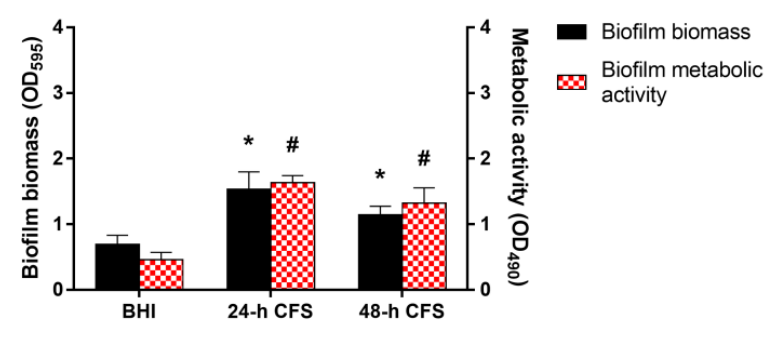

186

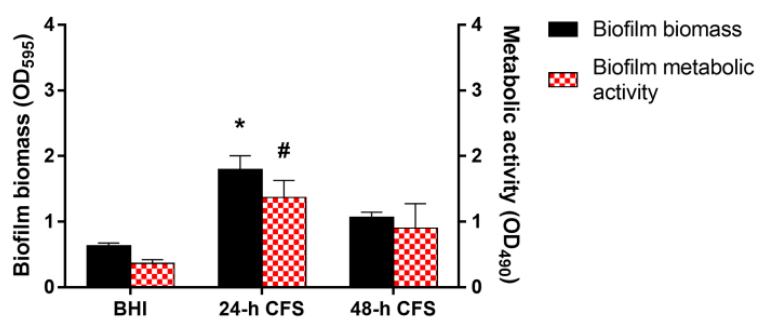

952

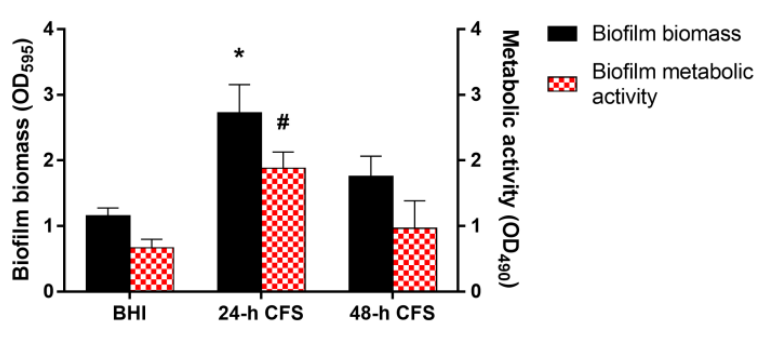

356

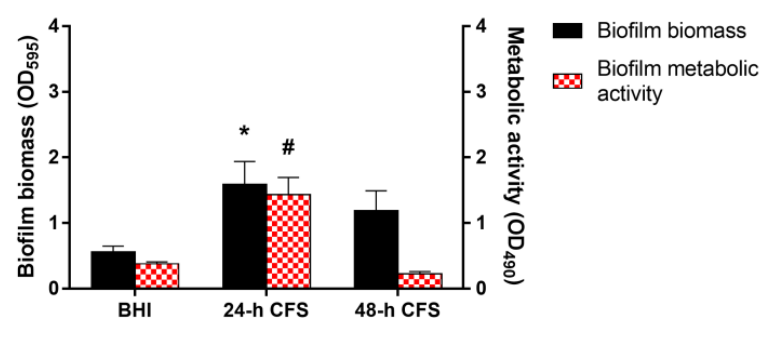

715

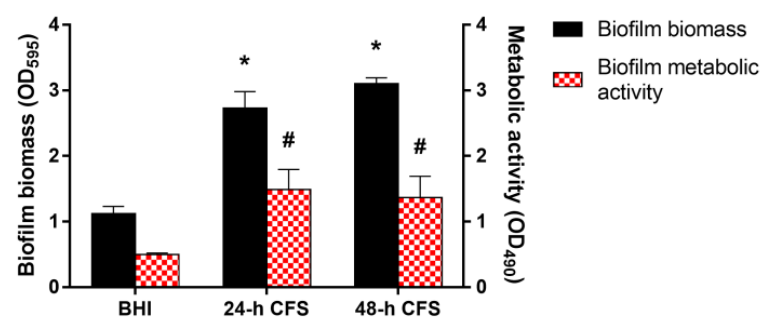

273

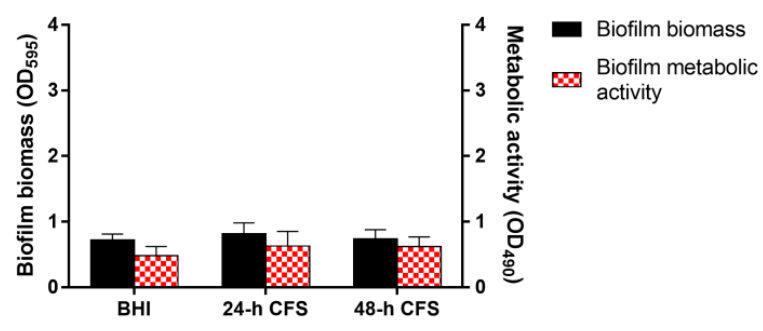

205

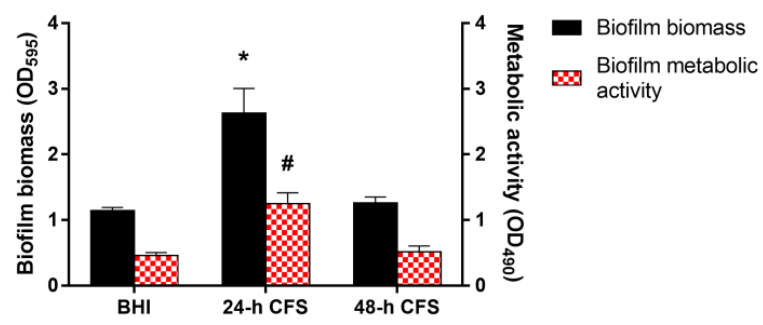

722

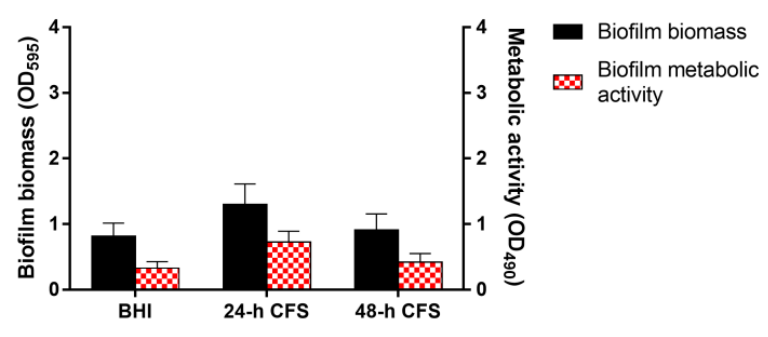

Figure 2. Effect of Lactobacillus iners cell-free supernatant (CFS) on in vitro biofilm formation by Candida albicans clinical isolates characterized as moderate $(305,244,715,186,273,952,205,722)$ and weak (356) biofilm producers. Biofilms of $C$. albicans clinical isolates were grown for $24 \mathrm{~h}$ using RPMI $1640+\mathrm{BHI}$ broth or 24/48 h L. iners CFS in a 1:1 ratio. Biofilm biomass was evaluated using the crystal violet staining method ( $\mathrm{OD}_{595}$, black bars, left y-axis), and metabolic activity was 
determined using the XTT reduction assay $\left(\mathrm{OD}_{490}\right.$, red bars, right y-axis). Values represent mean $\pm \mathrm{SEM}$ of at least three independent experiments performed in triplicate. Statistically significant differences were tested using one-way analysis of variance or Kruskal-Wallis test. ${ }^{*} p<0.05$ biomass of biofilm grown with $24 / 48 \mathrm{~h} \mathrm{~L}$. iners CFS vs. control biofilm biomass (BHI). ${ }^{\#} p<0.05$ metabolic activity of biofilm grown with $24 / 48 \mathrm{~h}$ L. iners CFS vs. control biofilm metabolic activity (BHI).

In contrast, L. iners 24 or 48 h CFS had no effects on the ability of strong biofilm producers to form biofilms (Figure 3).

263

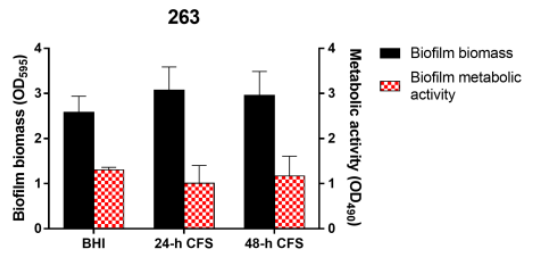

453

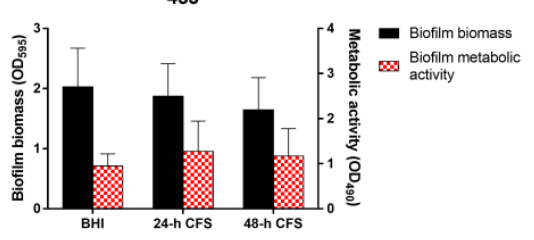

824

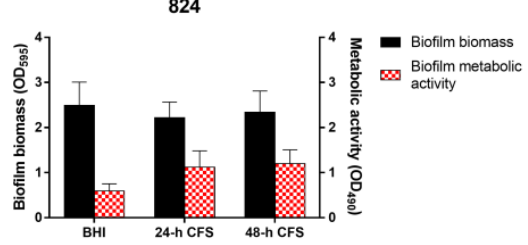

530

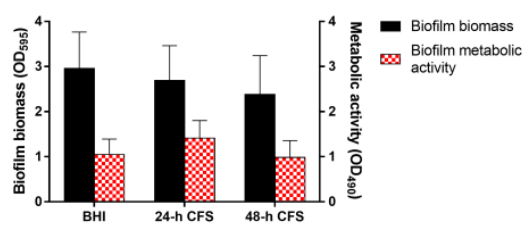

439

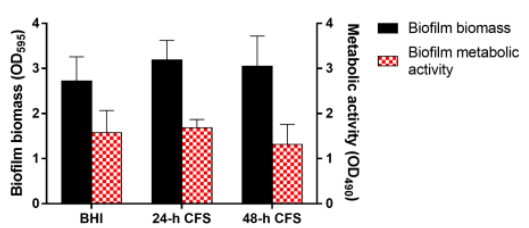

ATCC 10231

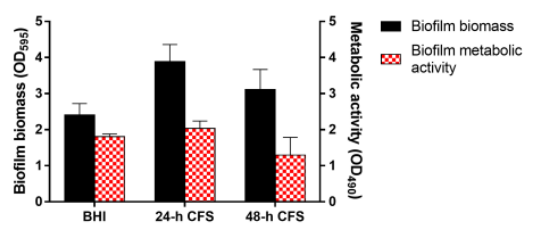

Figure 3. Effect of Lactobacillus iners cell-free supernatant (CFS) on in vitro biofilm formation by Candida albicans clinical isolates characterized as strong biofilm producers and C. albicans ATCC 10231 reference strain. Biofilms of C. albicans clinical isolates and reference strain were grown for $24 \mathrm{~h}$ using RPMI $1640+\mathrm{BHI}$ broth or 24/48 h L. iners CFS in a 1:1 ratio. Biofilm biomass was evaluated using the crystal violet staining method ( $\mathrm{OD}_{595}$, black bars, left y-axis), and metabolic activity was determined using the XTT reduction assay $\left(\mathrm{OD}_{490}\right.$, red bars, right y-axis). Values represent mean $\pm \mathrm{SEM}$ of at least three independent experiments performed in triplicate. Statistically significant differences were tested using one-way analysis of variance or Kruskal-Wallis test.

We also determined the $\mathrm{pH}$ of $C$. albicans biofilms developed in the absence or presence of $L$. iners $24 \mathrm{~h}$ CFS. C. albicans biofilm cultures showed a $\mathrm{pH}$ value of 6.4 , indicating that $\mathrm{pH}$ was not significantly modulated and maintained near neutral.

\subsection{Effects of L. iners CFS on C. albicans Biofilm Morphology}

The yeast-to-hyphal transition is a key feature of biofilm formation by C. albicans. Herein we investigated the effects of L. iners $24 \mathrm{~h}$ CFS on C. albicans biofilm morphology. As shown in Figure 4, in comparison to respective controls, L. iners culture supernatants induced an increase in the growth of C. albicans filamentous forms by all moderate (305, $244,715,186,273,952,205,722)$ and weak (356) biofilm producers. In contrast, L. iners CFS did not affect hyphal growth in strong biofilm producers (clinical isolates or reference strain) (Supplementary Figure S1). 
$\mathrm{BHI}$
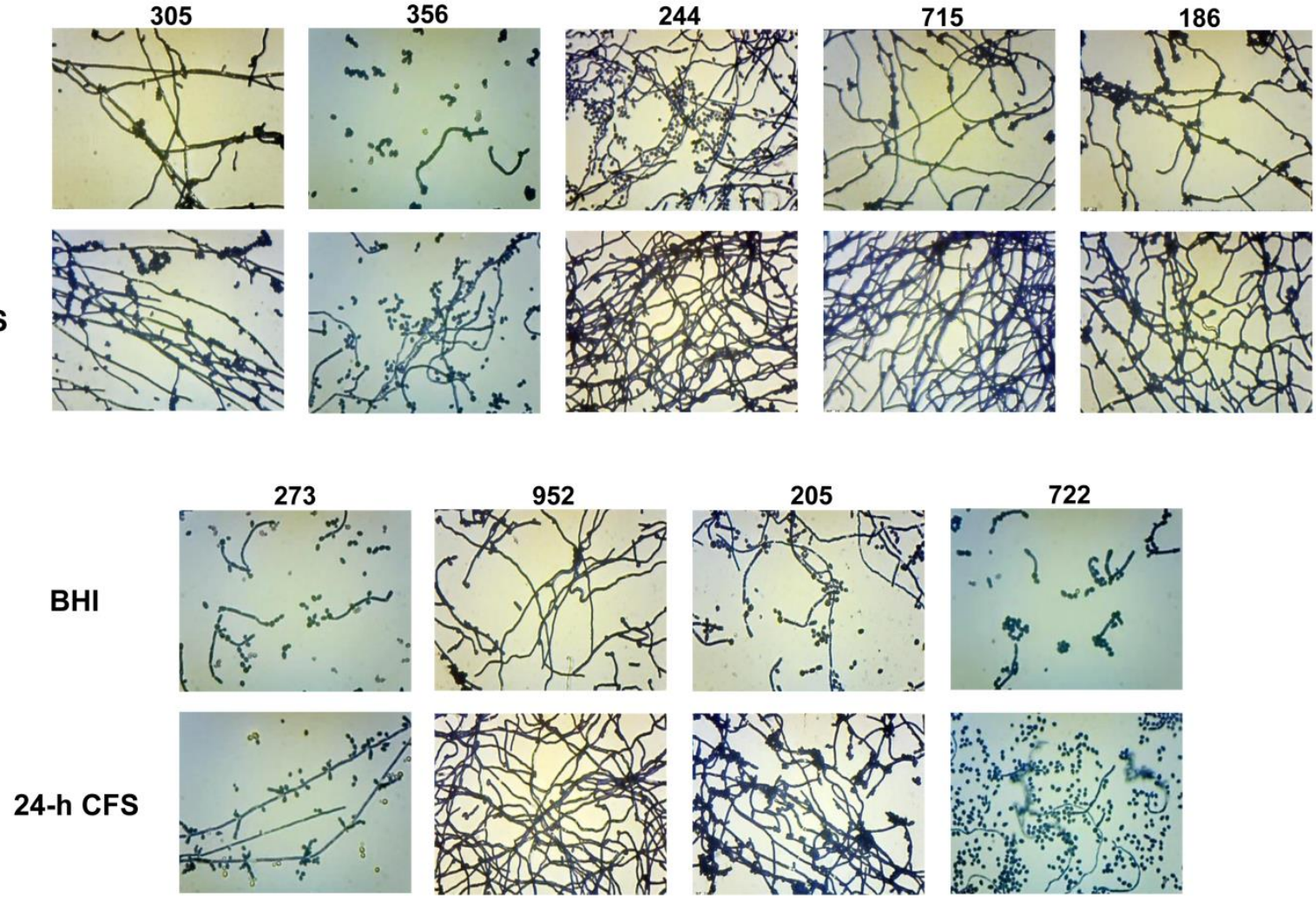

Figure 4. Effect of Lactobacillus iners cell-free supernatant (CFS) on biofilm morphology of Candida albicans clinical isolates characterized as moderate $(305,244,715,186,273,952,205,722)$ and weak (356) biofilm producers. Biofilms of $C$. albicans clinical isolates were grown for $24 \mathrm{~h}$ using RPMI $1640+\mathrm{BHI}$ broth or $24 \mathrm{~h} \mathrm{~L}$. iners CFS in a 1:1 ratio and stained with crystal violet. Images of biofilms were acquired with an inverted light microscope at $200 \times$. Representative microscopic images from three different experiments are shown.

The biofilm morphology of all the moderate/weak isolates $(n=7)$ which showed an increase in both biofilm formation as well as filamentous growth was further microscopically analyzed at magnification $400 \times$. Relative to respective controls (BHI), in the presence of L. iners $24 \mathrm{~h}$ CFS, we observed that apart from the clinical isolate 186 that formed a biofilm predominantly composed of clusters of yeast cells and pseudohyphae, and the strains 952 and 715, which formed true hyphae, all the remaining strains tested produced biofilms that were composed of both the filamentous forms (Figure 5). In addition, for all moderate/weak biofilm producers, we investigated the effects of $\mathrm{pH}$ on pseudohyphal/hyphal growth induced by L. iners $24 \mathrm{~h}$ CFS. We observed C. albicans biofilm formation at $\mathrm{pH} 4.9$. All tested strains failed to produce hyphae, and thus, resultant biofilms were composed of only clusters of yeast cells (data not shown). 

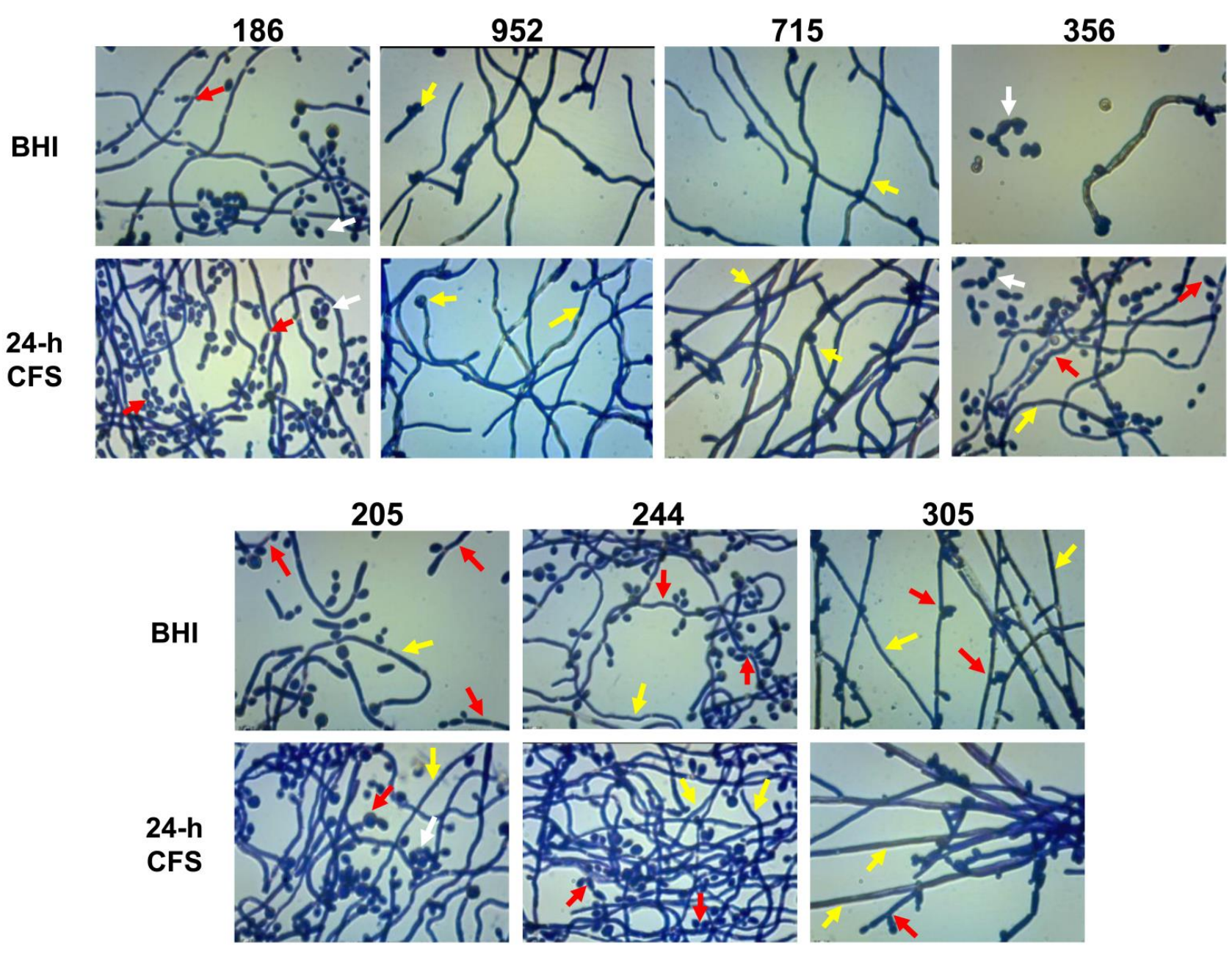

Figure 5. Lactobacillus iners cell-free supernatant (CFS) promotes filamentous growth by Candida albicans. The effect of $L$. iners CFS on hyphal/pseudohyphal growth of C. albicans characterized as moderate/weak biofilm producers was microscopically determined after crystal violet staining. Optical microscopy images (magnification $400 \times$ ) of C. albicans isolates showed that the hyphae/pseudohyphae mass was significantly higher in the presence of L. iners CFS than in controls cultured in BHI. Red arrows show branched C. albicans pseudohyphae, which appear ellipsoidal in shape, pointing to constrictions at septal sites, bearing single or multiple lateral blastoconidia. Yellow arrows show well-structured biofilms mainly composed of hyphae characterized as unconstricted filaments with parallel-sided walls and true septa. Clusters of unicellular oval or spherical yeasts (white arrows), some of them replicating as budding daughter cells, are also shown.

\subsection{L. iners Culture Supernatants Upregulated the Expression of C. albicans Hyphal-Specific Genes}

Our previous studies have shown that two key hyphae-associated genes, ECE1 and HWP1 [34-36], were overexpressed during human vaginal candidiasis, and that their upregulation was associated with NLRP3 inflammasome activation, a crucial player in the immunopathogenesis of VVC [29,37]. Based on these results, here we analyzed their expression level to gain insights into the mechanism by which $L$. iners $24 \mathrm{~h}$ CFS can modulate the pseudohyphal/hyphal growth in C. albicans.

Three moderate biofilm producers were chosen: the isolate 186 forming only pseudohyphae and the 952 and 715 forming only true hyphae. Transcriptional levels were quantified by qRT-PCR. The expression level of each gene was normalized with that of a housekeeping gene (ACT1) for $24 \mathrm{~h}$ CFS-treated as well as -untreated C. albicans biofilms; data are presented as relative expression fold change. In comparison with the control, L. iners $24 \mathrm{~h} \mathrm{CFS} \mathrm{significantly} \mathrm{upregulated} \mathrm{the} \mathrm{expression} \mathrm{levels} \mathrm{of} \mathrm{HWP1} \mathrm{and} \mathrm{ECE1} \mathrm{in} \mathrm{all}$ three and two of the three moderate biofilm producers, respectively (Figure 6). 
A

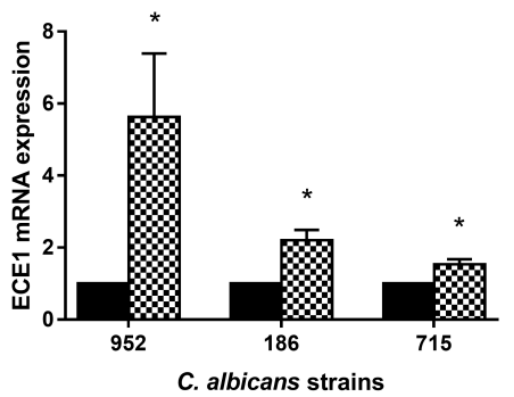

BHI

B 24-h CFS

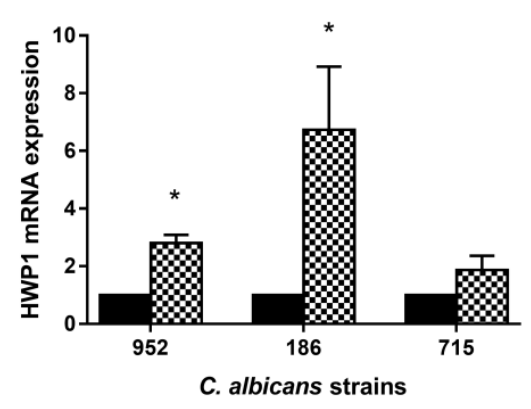

BH 24-h CFS

B
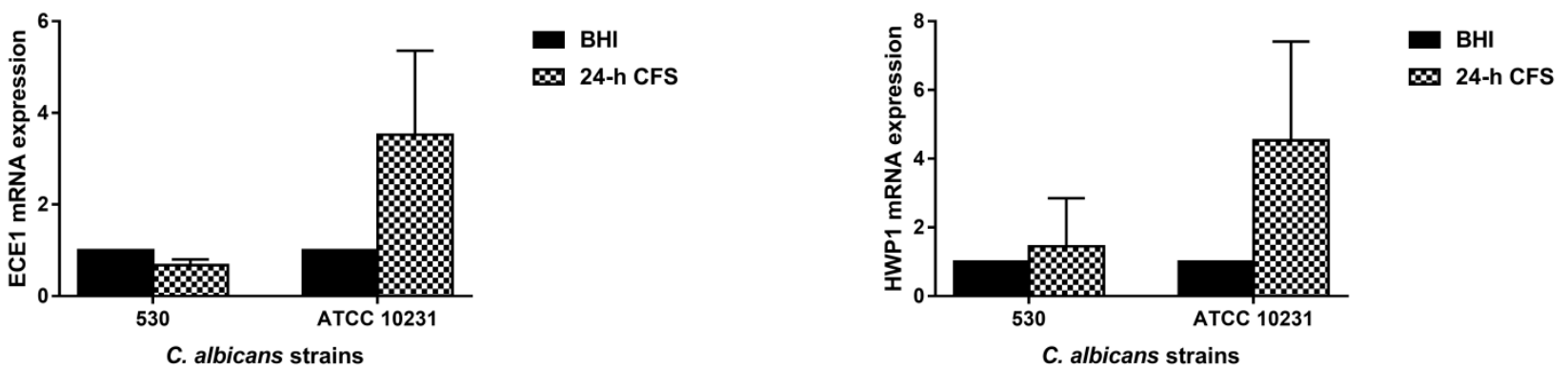

Figure 6. Effect of Lactobacillus iners $24 \mathrm{~h}$ cell-free supernatant (CFS) on the expression of hyphal-specific genes of Candida albicans clinical isolates and C. albicans ATCC 10231 reference strain. Total RNA was extracted from biofilms grown with or without $24 \mathrm{~h}$ L. iners CFS, retrotranscribed into CDNA, and real-time PCR was performed to assess expression of ACT1, ECE1, and HWP1. (A) Relative gene expression levels of ECE1 and HWP1 of three C. albicans clinical isolates characterized as moderate biofilm producers and (B) one characterized as strong biofilm producer with the ATCC 10231 reference strain. Data were analyzed using the $2^{-\Delta \Delta \mathrm{Ct}}$ method, and values represent mean \pm SEM of three (panel A) and two (panel B) independent experiments performed in triplicate. Statistically significant differences were tested with paired Student's $t$-test or Wilcoxon matched-pairs signed-rank test. ${ }^{*} p<0.05$ relative gene expression of $24 \mathrm{~h} \mathrm{~L}$. iners CFS-treated biofilms vs. control biofilms.

Transcriptional levels were also analyzed in two strong biofilm producers (one clinical isolate, 530, and the reference strain ATCC 10231), but L. iners CFS did not significantly modulate the expression levels of HWP1 or ECE1 in them.

\section{Discussion}

C. albicans is a common commensal fungus of the vaginal mucosa and also a pathogen that is responsible for almost $90 \%$ of all VVC cases [38]. It was recently reported that VVCpositive women present a depletion in the populations of health-associated Lactobacillus spp., such as L. crispatus. A decrease in the population of L. crispatus is associated with an increase in that of L. iners $[13,20]$, an unusual Lactobacillus species that does not seem to have a protective effect against VVC $[23,28]$. Deciphering the interaction between C. albicans and L. iners is crucial for increasing our knowledge of $C$. albicans pathogenicity and for developing new diagnostic tools and effective therapeutic approaches.

The ability of $C$. albicans to produce biofilms is considered to be one of the most important determinants of this common gynecological disease [38] and a critical factor responsible for conferring resistance to antimycotic drugs, such as fluconazole and amphotericin B [11,39-41], and consequently for RVVC development. To the best of our knowledge, we investigated, for the first time, the in vitro effects of $L$. iners CFS on the biofilm formation ability of $C$. albicans vaginal isolates. We found that $L$. iners CFS enhanced the biofilm-formation ability of several C. albicans isolates. According to previous stud- 
ies $[13,14,41]$, vaginal isolates display an ability to form mature, heterogeneous biofilms. We observed that L. iners CFS induced a significant increase in both biofilm biomass and metabolic activity of $77.7 \%$ of $C$. albicans clinical isolates that were moderate or weak biofilm producers, transforming them from moderate or weak biofilm producers to strong biofilm producers and consequently increasing their virulence. Indeed, clinical isolates capable of forming robust, well-structured biofilms are more pathogenic than weak biofilm producers $[41,42]$. These data suggest that $L$. iners-dominated vaginal microbiome can not only contribute to the onset of VVC, but also affect the management of such infections, increasing the probability of recurrence. McKloud et al. [13] suggested that women experiencing RVVC for $>6$ months show an imbalance of the vaginal microbiota, characterized by an abundance of L. iners and a reduction in health-associated Lactobacillus spp. Besides, McKloud et al. [13] demonstrated that $L$. iners was unable to modulate biofilm formation by C. albicans. One reason for this apparent discrepancy with our data could be differences in experimental conditions. We studied the effects of L. iners CFS on the biofilm formation ability of C. albicans clinical isolates, whereas McKloud et al. used reference strains of L. iners and C. albicans (DSMZ 13,335 and 5314, respectively). Furthermore, McKloud et al. used C. albicans and L. iners cocultures, instead of L. iners CFS.

The ability to produce filamentous forms is critical for the development and maintenance of $C$. albicans biofilms $[8,10,43,44]$. We found that $L$. iners CFS enhanced the growth of the filamentous forms only in those strains that became strong biofilm producers from moderate or weak biofilm producers. Our findings are consistent with those of previous studies, indicating a direct relationship between the ability of $C$. albicans to form biofilms and pseudohyphal/hyphal growth [45-47]. Therefore, it is possible that L. iners-dominated vaginal microbiome favors the formation of robust, stable $C$. albicans biofilms on the vaginal mucosa as well as on implanted devices, such as intrauterine devices [48], which is one of the most used methods to prevent fertilization [49]. It is well-established that $\mathrm{pH}$ plays a key role in the yeast-to-hyphal morphogenetic transition [35,50]; neutral $\mathrm{pH}$ provides a permissive environment for hyphal formation [51], while low $\mathrm{pH}$ prevents hyphal formation, thus promoting the growth of fungus as yeast cells [52]. Our data showed that the $\mathrm{pH}$ of $C$. albicans biofilms was near neutral, and that the presence of $L$. iners CFS, differently to other lactobacilli [53-55], did not reduce the $\mathrm{pH}$ value. This could be because $L$. iners produces less lactic acid than L. crispatus, and lactic acid is the main acidifier in the vaginal environment [56,57]. Considering that $C$. albicans is capable of alkalinizing the external environment [51], it is possible that in vaginal econiches where $C$. albicans coexists with L. iners, the $\mathrm{pH}$ is less acidic or even near neutral.

To elucidate the potential mechanism underlying the ability of $L$. iners to induce the growth of filamentous forms of $C$. albicans, we also assessed the expression levels of HWP1 and ECE1, which encode proteins essential for hyphal formation and play a key role in, at least, two phases of VVC pathogenesis: adhesion and tissue damage. In particular, HWP1 is crucial for C. albicans adhesion; it promotes its binding to epithelial cells, enabling colonization $[58,59]$ and biofilm formation [12,60-62]. ECE1 is highly expressed by hyphae during the invasion of epithelial cells. It encodes candidalysin, a toxin recently identified by Moyes et al. [7], which directly damages host epithelial membranes, triggering a danger-response signaling pathway with consequent activation of the epithelial immune response [63]. Our results showed that $L$. iners CFS upregulated the expression of both HWP1 and ECE1. These results are in line with those of our previous studies, which reported an overexpression of these genes in vaginal swabs of symptomatic women with VVC $[29,37]$. The limitations of this study are the small number of $C$. albicans clinical isolates tested and the use of L. iners CFS instead of live bacteria, which could be more representative of all the interactions occurring in vivo. A further limitation is that of not having tested supernatants from clinical isolates of L. iners. Their use would be helpful in confirming our data.

Overall, our findings demonstrate that $L$. iners promotes C. albicans virulence by enhancing pseudohyphal/hyphal growth and biofilm formation by moderate and weak 
biofilm producers, implying that the presence of L. iners in the vaginal environment, unlike other Lactobacillus spp., might not be a good indicator of vaginal health. Further in vitro and in vivo studies are warranted on this intriguing topic.

Supplementary Materials: The following are available online at https:/ / www.mdpi.com/article/10 .3390 / microorganisms9122577/s1. Figure S1. Effect of Lactobacillus iners cell-free supernatant (CFS) on biofilm morphology of Candida albicans clinical isolates characterized as strong biofilm producers.

Author Contributions: Conceptualization, C.M. and S.S.; methodology, S.S., S.V., M.G., E.L.; validation, S.S. and C.M.; formal analysis, S.S., S.V., M.G., E.N., S.R., R.G. and S.P.; investigation, S.S. and S.V.; resources, C.M.; writing-original draft preparation, S.S., C.M. and R.G.; writing-review and editing, R.G. and C.M.; supervision, C.M.; funding acquisition, C.M. All authors approved the submitted version and agree to be personally accountable for the author's own contributions and for ensuring that questions related to the accuracy or integrity of any part of the work, even the ones in which the author was not personally involved, are appropriately investigated, resolved, and documented in the literature. All authors have read and agreed to the published version of the manuscript.

Funding: This research was funded by University of Perugia (Departmental funds for basic research2019-Monari).

Institutional Review Board Statement: The study was conducted according to the guidelines of the Declaration of Helsinki, and approved by local ethical committee (Comitato Etico delle Aziende Sanitarie, Umbria, Italy) protocol code CA 2020, 3802/19 (16 September 2020).

Informed Consent Statement: Informed consent was obtained from all subjects involved in the study.

Data Availability Statement: The datasets used and/or analyzed during the current study are available from the corresponding author on reasonable request.

Conflicts of Interest: The authors declare no conflict of interest.

\section{References}

1. Sobel, J.D. Vulvovaginal candidosis. Lancet 2007, 369, 1961-1971. [CrossRef]

2. Aballea, S.; Guelfucci, F.; Wagner, J.; Khemiri, A.; Dietz, J.P.; Sobel, J.; Toumi, M. Subjective health status and health-related quality of life among women with Recurrent Vulvovaginal Candidosis (RVVC) in Europe and the USA. Health Qual. Life Outcomes 2013, 11, 169. [CrossRef] [PubMed]

3. Ehrstrom, S.M.; Kornfeld, D.; Thuresson, J.; Rylander, E. Signs of chronic stress in women with recurrent candida vulvovaginitis. Am. J. Obstet. Gynecol. 2005, 193, 1376-1381. [CrossRef] [PubMed]

4. Kennedy, M.A.; Sobel, J.D. Vulvovaginal Candidiasis Caused by Non-albicans Candida Species: New Insights. Curr. Infect. Dis. Rep. 2010, 12, 465-470. [CrossRef]

5. Goncalves, B.; Ferreira, C.; Alves, C.T.; Henriques, M.; Azeredo, J.; Silva, S. Vulvovaginal candidiasis: Epidemiology, microbiology and risk factors. Crit. Rev. Microbiol. 2016, 42, 905-927. [CrossRef]

6. Mayer, F.L.; Wilson, D.; Hube, B. Candida albicans pathogenicity mechanisms. Virulence 2013, 4, 119-128. [CrossRef]

7. Moyes, D.L.; Wilson, D.; Richardson, J.P.; Mogavero, S.; Tang, S.X.; Wernecke, J.; Hofs, S.; Gratacap, R.L.; Robbins, J.; Runglall, M.; et al. Candidalysin is a fungal peptide toxin critical for mucosal infection. Nature 2016, 532, 64-68. [CrossRef]

8. Ponde, N.O.; Lortal, L.; Ramage, G.; Naglik, J.R.; Richardson, J.P. Candida albicans biofilms and polymicrobial interactions. Crit. Rev. Microbiol. 2021, 47, 91-111. [CrossRef]

9. Chandra, J.; Kuhn, D.M.; Mukherjee, P.K.; Hoyer, L.L.; McCormick, T.; Ghannoum, M.A. Biofilm formation by the fungal pathogen Candida albicans: Development, architecture, and drug resistance. J. Bacteriol. 2001, 183, 5385-5394. [CrossRef]

10. Harriott, M.M.; Noverr, M.C. Candida albicans and Staphylococcus aureus form polymicrobial biofilms: Effects on antimicrobial resistance. Antimicrob. Agents Chemother. 2009, 53, 3914-3922. [CrossRef]

11. Harriott, M.M.; Lilly, E.A.; Rodriguez, T.E.; Fidel, P.L.; Noverr, M.C. Candida albicans forms biofilms on the vaginal mucosa. Microbiology 2010, 156, 3635-3644. [CrossRef]

12. Rodriguez-Cerdeira, C.; Martinez-Herrera, E.; Carnero-Gregorio, M.; Lopez-Barcenas, A.; Fabbrocini, G.; Fida, M.; El-Samahy, M.; Gonzalez-Cespon, J.L. Pathogenesis and Clinical Relevance of Candida Biofilms in Vulvovaginal Candidiasis. Front. Microbiol. 2020, 11, 544480. [CrossRef]

13. McKloud, E.; Delaney, C.; Sherry, L.; Kean, R.; Williams, S.; Metcalfe, R.; Thomas, R.; Richardson, R.; Gerasimidis, K.; Nile, C.J.; et al. Recurrent Vulvovaginal Candidiasis: A Dynamic Interkingdom Biofilm Disease of Candida and Lactobacillus. mSystems 2021, 6, e0062221. [CrossRef] 
14. Sherry, L.; Kean, R.; McKloud, E.; O’Donnell, L.E.; Metcalfe, R.; Jones, B.L.; Ramage, G. Biofilms Formed by Isolates from Recurrent Vulvovaginal Candidiasis Patients Are Heterogeneous and Insensitive to Fluconazole. Antimicrob. Agents Chemother. 2017, 61, e01065-17. [CrossRef]

15. Rodriguez-Cerdeira, C.; Gregorio, M.C.; Molares-Vila, A.; Lopez-Barcenas, A.; Fabbrocini, G.; Bardhi, B.; Sinani, A.; SanchezBlanco, E.; Arenas-Guzman, R.; Hernandez-Castro, R. Biofilms and vulvovaginal candidiasis. Colloids Surf. B Biointerfaces 2019, 174, 110-125. [CrossRef]

16. Wu, X.; Zhang, S.; Li, H.; Shen, L.; Dong, C.; Sun, Y.; Chen, H.; Xu, B.; Zhuang, W.; Deighton, M.; et al. Biofilm Formation of Candida albicans Facilitates Fungal Infiltration and Persister Cell Formation in Vaginal Candidiasis. Front. Microbiol. 2020, $11,1117$. [CrossRef]

17. Silva, S.; Rodrigues, C.F.; Araujo, D.; Rodrigues, M.E.; Henriques, M. Candida Species Biofilms' Antifungal Resistance. J. Fungi 2017, 3, 8. [CrossRef]

18. Petrova, M.I.; Lievens, E.; Malik, S.; Imholz, N.; Lebeer, S. Lactobacillus species as biomarkers and agents that can promote various aspects of vaginal health. Front. Physiol. 2015, 6, 81. [CrossRef]

19. Ravel, J.; Gajer, P.; Abdo, Z.; Schneider, G.M.; Koenig, S.S.; McCulle, S.L.; Karlebach, S.; Gorle, R.; Russell, J.; Tacket, C.O.; et al. Vaginal microbiome of reproductive-age women. Proc. Natl. Acad. Sci. USA 2011, 108 (Suppl. 1), 4680-4687. [CrossRef]

20. Ceccarani, C.; Foschi, C.; Parolin, C.; D’Antuono, A.; Gaspari, V.; Consolandi, C.; Laghi, L.; Camboni, T.; Vitali, B.; Severgnini, M.; et al. Diversity of vaginal microbiome and metabolome during genital infections. Sci. Rep. 2019, 9, 14095. [CrossRef]

21. Kalia, N.; Singh, J.; Kaur, M. Microbiota in vaginal health and pathogenesis of recurrent vulvovaginal infections: A critical review. Ann. Clin. Microbiol. Antimicrob. 2020, 19, 5. [CrossRef]

22. Tortelli, B.A.; Lewis, W.G.; Allsworth, J.E.; Member-Meneh, N.; Foster, L.R.; Reno, H.E.; Peipert, J.F.; Fay, J.C.; Lewis, A.L. Associations between the vaginal microbiome and Candida colonization in women of reproductive age. Am. J. Obstet. Gynecol. 2020, 222, 471.e1-471.e9. [CrossRef]

23. Vaneechoutte, M. Lactobacillus iners, the unusual suspect. Res. Microbiol. 2017, 168, 826-836. [CrossRef]

24. Rampersaud, R.; Planet, P.J.; Randis, T.M.; Kulkarni, R.; Aguilar, J.L.; Lehrer, R.I.; Ratner, A.J. Inerolysin, a cholesterol-dependent cytolysin produced by Lactobacillus iners. J. Bacteriol. 2011, 193, 1034-1041. [CrossRef]

25. Bayar, E.; Bennett, P.R.; Chan, D.; Sykes, L.; MacIntyre, D.A. The pregnancy microbiome and preterm birth. Semin. Immunopathol. 2020, 42, 487-499. [CrossRef]

26. Zheng, N.; Guo, R.; Yao, Y.; Jin, M.; Cheng, Y.; Ling, Z. Lactobacillus iners Is Associated with Vaginal Dysbiosis in Healthy Pregnant Women: A Preliminary Study. Biomed. Res. Int. 2019, 2019, 6079734. [CrossRef]

27. Campisciano, G.; Iebba, V.; Zito, G.; Luppi, S.; Martinelli, M.; Fischer, L.; De Seta, F.; Basile, G.; Ricci, G.; Comar, M. Lactobacillus iners and gasseri, Prevotella bivia and HPV Belong to the Microbiological Signature Negatively Affecting Human Reproduction. Microorganisms 2020, 9, 39. [CrossRef]

28. Petrova, M.I.; Reid, G.; Vaneechoutte, M.; Lebeer, S. Lactobacillus iners: Friend or Foe? Trends Microbiol. 2017, $25,182-191$. [CrossRef]

29. Roselletti, E.; Monari, C.; Sabbatini, S.; Perito, S.; Vecchiarelli, A.; Sobel, J.D.; Cassone, A. A Role for Yeast/Pseudohyphal Cells of Candida albicans in the Correlated Expression of NLRP3 Inflammasome Inducers in Women with Acute Vulvovaginal Candidiasis. Front. Microbiol. 2019, 10, 2669. [CrossRef]

30. Roselletti, E.; Perito, S.; Sabbatini, S.; Monari, C.; Vecchiarelli, A. Vaginal Epithelial Cells Discriminate Between Yeast and Hyphae of Candida albicans in Women Who Are Colonized or Have Vaginal Candidiasis. J. Infect. Dis. 2019, 220, 1645-1654. [CrossRef]

31. Sabbatini, S.; Monari, C.; Ballet, N.; Decherf, A.C.; Bozza, S.; Camilloni, B.; Perito, S.; Vecchiarelli, A. Anti-Biofilm Properties of Saccharomyces cerevisiae CNCM I-3856 and Lacticaseibacillus rhamnosus ATCC 53103 Probiotics against G. vaginalis. Microorganisms 2020, 8, 1294. [CrossRef] [PubMed]

32. Gulati, M.; Lohse, M.B.; Ennis, C.L.; Gonzalez, R.E.; Perry, A.M.; Bapat, P.; Arevalo, A.V.; Rodriguez, D.L.; Nobile, C.J. In Vitro Culturing and Screening of Candida albicans Biofilms. Curr. Protoc. Microbiol. 2018, 50, e60. [CrossRef] [PubMed]

33. Stepanovic, S.; Vukovic, D.; Hola, V.; Di Bonaventura, G.; Djukic, S.; Cirkovic, I.; Ruzicka, F. Quantification of biofilm in microtiter plates: Overview of testing conditions and practical recommendations for assessment of biofilm production by staphylococci. APMIS 2007, 115, 891-899. [CrossRef] [PubMed]

34. Tsuchimori, N.; Sharkey, L.L.; Fonzi, W.A.; French, S.W.; Edwards, J.E., Jr.; Filler, S.G. Reduced virulence of HWP1-deficient mutants of Candida albicans and their interactions with host cells. Infect. Immun. 2000, 68, 1997-2002. [CrossRef] [PubMed]

35. Sudbery, P.E. Growth of Candida albicans hyphae. Nat. Rev. Microbiol. 2011, 9, 737-748. [CrossRef]

36. Finkel, J.S.; Mitchell, A.P. Genetic control of Candida albicans biofilm development. Nat. Rev. Microbiol. 2011, 9, 109-118. [CrossRef]

37. Roselletti, E.; Perito, S.; Gabrielli, E.; Mencacci, A.; Pericolini, E.; Sabbatini, S.; Cassone, A.; Vecchiarelli, A. NLRP3 inflammasome is a key player in human vulvovaginal disease caused by Candida albicans. Sci. Rep. 2017, 7, 17877. [CrossRef]

38. Gaziano, R.; Sabbatini, S.; Roselletti, E.; Perito, S.; Monari, C. Saccharomyces cerevisiae-Based Probiotics as Novel Antimicrobial Agents to Prevent and Treat Vaginal Infections. Front. Microbiol. 2020, 11, 718. [CrossRef]

39. Gao, M.; Wang, H.; Zhu, L. Quercetin Assists Fluconazole to Inhibit Biofilm Formations of Fluconazole-Resistant Candida Albicans in In Vitro and In Vivo Antifungal Managements of Vulvovaginal Candidiasis. Cell. Physiol. Biochem. 2016, 40, 727-742. [CrossRef]

40. Muzny, C.A.; Schwebke, J.R. Biofilms: An Underappreciated Mechanism of Treatment Failure and Recurrence in Vaginal Infections. Clin. Infect. Dis. 2015, 61, 601-606. [CrossRef] 
41. Sherry, L.; Rajendran, R.; Lappin, D.F.; Borghi, E.; Perdoni, F.; Falleni, M.; Tosi, D.; Smith, K.; Williams, C.; Jones, B.; et al. Biofilms formed by Candida albicans bloodstream isolates display phenotypic and transcriptional heterogeneity that are associated with resistance and pathogenicity. BMC Microbiol. 2014, 14, 182. [CrossRef]

42. Rajendran, R.; May, A.; Sherry, L.; Kean, R.; Williams, C.; Jones, B.L.; Burgess, K.V.; Heringa, J.; Abeln, S.; Brandt, B.W.; et al. Integrating Candida albicans metabolism with biofilm heterogeneity by transcriptome mapping. Sci. Rep. 2016, 6, 35436. [CrossRef]

43. Lopez-Ribot, J.L. Candida albicans biofilms: More than filamentation. Curr. Biol. 2005, 15, R453-R455. [CrossRef]

44. Nobile, C.J.; Johnson, A.D. Candida albicans Biofilms and Human Disease. Annu. Rev. Microbiol. 2015, 69, 71-92. [CrossRef]

45. Banerjee, M.; Uppuluri, P.; Zhao, X.R.; Carlisle, P.L.; Vipulanandan, G.; Villar, C.C.; Lopez-Ribot, J.L.; Kadosh, D. Expression of UME6, a key regulator of Candida albicans hyphal development, enhances biofilm formation via Hgc1- and Sun41-dependent mechanisms. Eukaryot Cell 2013, 12, 224-232. [CrossRef]

46. Ramage, G.; VandeWalle, K.; Lopez-Ribot, J.L.; Wickes, B.L. The filamentation pathway controlled by the Efg1 regulator protein is required for normal biofilm formation and development in Candida albicans. FEMS Microbiol. Lett. 2002, 214, 95-100. [CrossRef]

47. Banerjee, M.; Thompson, D.S.; Lazzell, A.; Carlisle, P.L.; Pierce, C.; Monteagudo, C.; Lopez-Ribot, J.L.; Kadosh, D. UME6, a novel filament-specific regulator of Candida albicans hyphal extension and virulence. Mol. Biol. Cell 2008, 19, 1354-1365. [CrossRef]

48. Auler, M.E.; Morreira, D.; Rodrigues, F.F.; Abr Ao, M.S.; Margarido, P.F.; Matsumoto, F.E.; Silva, E.G.; Silva, B.C.; Schneider, R.P.; Paula, C.R. Biofilm formation on intrauterine devices in patients with recurrent vulvovaginal candidiasis. Med. Mycol. 2010, 48, 211-216. [CrossRef]

49. Pal, Z.; Urban, E.; Dosa, E.; Pal, A.; Nagy, E. Biofilm formation on intrauterine devices in relation to duration of use. J. Med. Microbiol. 2005, 54, 1199-1203. [CrossRef]

50. Hall, R.A.; Cottier, F.; Muhlschlegel, F.A. Molecular networks in the fungal pathogen Candida albicans. Adv. Appl. Microbiol. 2009, 67, 191-212. [CrossRef]

51. Vylkova, S.; Carman, A.J.; Danhof, H.A.; Collette, J.R.; Zhou, H.; Lorenz, M.C. The fungal pathogen Candida albicans autoinduces hyphal morphogenesis by raising extracellular pH. mBio 2011, 2, e00055-11. [CrossRef]

52. Davis, D. Adaptation to environmental $\mathrm{pH}$ in Candida albicans and its relation to pathogenesis. Curr. Genet. 2003, $44,1-7$. [CrossRef]

53. Jiang, Q.; Stamatova, I.; Kari, K.; Meurman, J.H. Inhibitory activity in vitro of probiotic lactobacilli against oral Candida under different fermentation conditions. Benef. Microbes 2015, 6, 361-368. [CrossRef]

54. Wang, S.; Wang, Q.; Yang, E.; Yan, L.; Li, T.; Zhuang, H. Antimicrobial Compounds Produced by Vaginal Lactobacillus crispatus Are Able to Strongly Inhibit Candida albicans Growth, Hyphal Formation and Regulate Virulence-related Gene Expressions. Front. Microbiol. 2017, 8, 564. [CrossRef]

55. Zangl, I.; Pap, I.J.; Aspock, C.; Schuller, C. The role of Lactobacillus species in the control of Candida via biotrophic interactions. Microb. Cell 2019, 7, 1-14. [CrossRef]

56. Witkin, S.S.; Mendes-Soares, H.; Linhares, I.M.; Jayaram, A.; Ledger, W.J.; Forney, L.J. Influence of vaginal bacteria and D- and L-lactic acid isomers on vaginal extracellular matrix metalloproteinase inducer: Implications for protection against upper genital tract infections. mBio 2013, 4, e00460-13. [CrossRef]

57. Tachedjian, G.; Aldunate, M.; Bradshaw, C.S.; Cone, R.A. The role of lactic acid production by probiotic Lactobacillus species in vaginal health. Res. Microbiol. 2017, 168, 782-792. [CrossRef]

58. Orsi, C.F.; Sabia, C.; Ardizzoni, A.; Colombari, B.; Neglia, R.G.; Peppoloni, S.; Morace, G.; Blasi, E. Inhibitory effects of different lactobacilli on Candida albicans hyphal formation and biofilm development. J. Biol. Regul. Homeost. Agents 2014, $28,743-752$.

59. Samot, J.; Rouabhia, M. Effect of Dermaseptin S4 on C. albicans Growth and EAP1 and HWP1 Gene Expression. Probiotics Antimicrob. Proteins 2021, 13, 287-298. [CrossRef]

60. Finkel, J.S.; Xu, W.; Huang, D.; Hill, E.M.; Desai, J.V.; Woolford, C.A.; Nett, J.E.; Taff, H.; Norice, C.T.; Andes, D.R.; et al. Portrait of Candida albicans adherence regulators. PLoS Pathog. 2012, 8, e1002525. [CrossRef]

61. Holland, L.M.; Schroder, M.S.; Turner, S.A.; Taff, H.; Andes, D.; Grozer, Z.; Gacser, A.; Ames, L.; Haynes, K.; Higgins, D.G.; et al. Comparative phenotypic analysis of the major fungal pathogens Candida parapsilosis and Candida albicans. PLoS Pathog. 2014, 10, e1004365. [CrossRef] [PubMed]

62. Su, C.; Yu, J.; Lu, Y. Hyphal development in Candida albicans from different cell states. Curr. Genet. 2018, 64, 1239-1243. [CrossRef] [PubMed]

63. Rogiers, O.; Frising, U.C.; Kucharikova, S.; Jabra-Rizk, M.A.; van Loo, G.; Van Dijck, P.; Wullaert, A. Candidalysin Crucially Contributes to Nlrp3 Inflammasome Activation by Candida albicans Hyphae. mBio 2019, 10, e02221-18. [CrossRef] [PubMed] 